\title{
Elder abuse and neglect: Past endeavours as a springboard for the future
}

\section{Glynnis Brook}

A Principal Academic staff member and the Programme Leader of the Bachelor of Social Work at the Christchurch Polytechnic Institute of Technology, Glynnis has a background in social work with older people. This includes working with older people and their families in a variety of areas and settings. Glynnis has an ongoing interest in the issue of elder abuse and neglect with a particular interest in the way social work practitioners think about and respond to elder mistreatment.

This paper traces the emergence of, and responses to, the phenomenon known as elder abuse and neglect in Aotearoa New Zealand and considers where to from here.

\section{Introduction}

The issue of elder mistreatment has been slow to emerge, with the primary response the development of services. After more than two decades the Ministry of Health states 'elder abuse remains an emerging issue' (MOH, 2007, p. 8). The Families Commission Report (2008, p. 12) and Fallon (2006) concur with the former noting a need to '... improv(e) understanding of the nature of elder abuse and neglect ... '. (Peri, Fanslow, Hand \& Parsons, 2008, p. 12) and Fallon (2006) claiming elder mistreatment remains largely out of sight, shadowy and under-recognised. A recent address by Patricia Fleischmann of the Toronto Police Service, 'Elder abuse: An emerging crime' (Christchurch, September, 2008), suggests that the 'awakening' has also been a lengthy process internationally. While recent media interest is evident, notably in response to the gagging incident at an Auckland rest home in June 2008 (Thompson, 2008 The Press p. A2), this interest tends to be temporary, focusing on isolated and sensational incidents. While many of us will (rightly) recall the names of James Whakaruru, Lillybing and Delcelia Whittaker, we are less likely to recall reported elder abuse and neglect let alone the name of any individual victim. This suggests that more is needed - a position advocated in this paper but tempered by the need to recognise past endeavours as a springboard for the future. The following sections review:

1. The endeavours of the past 20 years - practice, policy and research;

2. Definitional difficulties and approaches; and

3. The challenges for practice.

With the aim being to begin building a bridge spanning practice and research, this paper concludes that it is essential we seek, through critical analysis and reflexive processes, a greater understanding of the '... steps [needed] towards changing attitudes and behaviours towards elder abuse and neglect ... at the community and societal level' (Peri, et al., 2008, p. 12). 


\section{Past endeavours}

\section{The service response}

The mid-1980s saw a growing awareness of 'elder abuse and neglect'. This awareness trailed the 'discovery' of elder mistreatment in other nation states. In 1993 a new, Christchurchbased service - the Elder Abuse Resource Team - was among the first to be established in Aotearoa New Zealand (Maher, 2005), as a dedicated service working towards prevention and intervention in cases of elder maltreatment. This team was a multi-agency project funded by the New Zealand Lotteries Commission (Maher, 2005). The partners were: Age Concern Canterbury, a local not-for-profit organisation; Upper South Island Presbyterian Support Services (PSS), a religious welfare organisation; and Older Person's Health (OPH) (now part of the Canterbury District Health Board [CDHB]), a publicly funded service delivering regional health and hospital services to older people.

The team relied heavily on international literature:

- To learn about this phenomenon,

- To assist in the design of practice frameworks to support practitioners grappling with elder abuse, and

- In the implementation of education programmes intended to raise awareness.

The necessity to seek offshore experiences reflects the lack of local research at this time.

The Elder Abuse Resource Team's aim was twofold (Maher, 2005):

1. To provide a coordinated inter-agency approach achieved via cross-agency relationship building, community education and public awareness, and

2. To develop strategies that would encourage multi-agency case management

In its short history (1993-1998) the Elder Abuse Resource Team was reviewed, re-structured and renamed, with the 'new' look service reducing casework to $40 \%$ and increasing the educative component to 60\% (Maher, 2005). In July 1998 the Service ceased operation due to the inability to attract on-going funding. The void was filled by existing local agencies continuing to offer services - notably OPH and PSS.

From a national perspective, Age Concern New Zealand - the national umbrella group for Age Concern Canterbury - was funded by Child Youth and Family Service (CYFS), then by a restructured Ministry of Social Development (MSD) (MSD, 2006), to provide elder abuse and neglect initiatives. Currently 26 Elder Abuse and Neglect Prevention and Coordination of Intervention Services (EANP) operate throughout the country, 24 of which are part funded by MSD (McKendry, 2007; MSD, 2006). The aims of the EANP services are to:

- Provide information and advice to individuals experiencing mistreatment, and to carers, family/whanau,

- Facilitate a coordinated approach,

- Raise public awareness, and

- Encourage healthy ageing in line with the Aotearoa New Zealand Government's positive ageing strategy (Age Concern, 2006). 
Seven other providers of services exist, including specialist services for Maori and Pacifica peoples.

\section{The policy response}

From a policy perspective, elder abuse and neglect is identified on the policy agenda in the Positive Ageing Strategy (MSD, 2003), Te Rito: New Zealand Family Violence Strategy (MSD, 2002) and the Families Commission's Elder Abuse and Neglect: Exploration of risk and protective factors (Peri, et al., 2008). The 2002 strategy document resulted in the Family Violence Intervention Guidelines: Elder abuse and neglect being released in July 2007 - representing the last in this series which commenced with Child and Partner Abuse Guidelines (MoH, 2002). The 2007 guidelines acknowledge the multi-faceted nature of elder mistreatment citing Durie's (2001) Te Whare Tapa Wha model as a mechanism for understanding the phenomenon from a multi-dimensional perspective. However, while this policy document is prefaced by Durie's model, it makes comment that 'research on cultural perspectives is limited' (MoH, 2007, p. 15).

\section{The research response}

With regard to research, programme and service evaluations based on reported cases and quantitative analysis, particularly from the EANP services (Age Concern, 1995, 2004, 2005, 2006), have been central. While they provide some locally informed research, these analyses exclude data from the seven non-affiliated services and thereby data inclusive of specialised services for indigenous and Pacifica peoples. Further, this source of analysis represents only those cases that have come to the attention of the EANP services and does not capture potential data from 'large communities of older people currently without access to specialist EANP services ... living in sparsely populated rural areas' (Age Concern New Zealand, 2007, p. 16). The 2007 guidelines (MOH, 2007) identified the need for national research, a position supported by Age Concern (2006). To date no population-based study on elder abuse and neglect has been carried out, although some small, localised research projects have been completed (MOH, 2007).

While many social workers in Aotearoa New Zealand face the challenges of working with elder mistreatment in their everyday encounters with older clients, it appears few are engaged in any research activity. This reduces the opportunities for debate. This lack of social work research and debate appears incongruent with the level of practice-based experience of working with abused and neglected elders which is apparent within the local social work community. This may be a result of definitional disarray leading to research and practice uncertainty.

\section{Definition difficulties}

The literature attempts to define elder abuse and neglect but instead offers a perplexing picture. Variously titled as 'granny battering' (Burston, 1975), 'battered elder syndrome' (Block \& Sinnott, 1979) and 'elder mistreatment' (Hickey \& Douglass, 1981), the phrase has come to denote 'an all-inclusive term representing all types of mistreatment or abusive behaviour towards older adults' (Fallon, 2006, p. 5). While as a descriptive term 'elder abuse and neglect' has generic recognition, how to define it remains problematic. This preoccupation with meaning (Breckman, 1986; Pillemer \& Wolf, 1986; Ogg, 1993; Decalmer \& Glendenning, 1993; Harbison \& Morrow 1998; Pain, 1999; Schofield, 2004) has, according to Harris (2006), 
restricted our ability to investigate elder mistreatment from a perspective which considers both causation and context - a situation which generates imprecision and may account for the uncertainty reported by practitioners (Maher, 2005).

\section{The connotative and denotative approach to definition}

Stones (1995 as cited in Nahmaish 2002) documented diverse definitional approaches, noting a;

- Connotative approach which seeks to identify a single, comprehensive definition, and

- Denotative approach which identifies examples as a means to explanation.

These are both evident in the literature (O'Malley, Segel \& Perez, 1979; Johnson, 1986; Rathbourne-McCaun, 1980; O’Malley, Everett, O'Malley \& Campion, 1983; Fulmer \& O'Malley, 1987; Age Concern New Zealand, 1995, 2007; WHO, 2002), often used in combination providing an overarching statement alongside sub-categories seeking to add specificity. This joint approach is one reflected in Aotearoa New Zealand's current definition of:

... a single or repeated act or lack of appropriate action, occurring within any relationship where there is an expectation of trust, which causes harm or distress to an older person' $(\mathrm{MOH}$, 2007, p. 11).

This is accompanied by an inventory of recognised specific types: physical, sexual, psychological/emotional, financial / material and neglect (WHO, 2002; Schofield, 2004; Harris, 2006; Age Concern New Zealand, 2007). It is this combined approach which informs our understandings and serves as a baseline for intervention (Maher, 2005; MOH, 2007). Implied are the notions that:

- Elder abuse has specific, identifiable features which can be known, detected, ordered and managed with a degree of objectivity and certainty through guideline formulation, and

- Practitioners can use guidelines to differentiate features in a way which is meaningful for practice - a position promoted by Pritchard (1999, p 18) who asserts that 'social workers should be compelled never to avoid guidelines'.

While this approach enables practitioners to focus on 'known' categories, fashion responses accordingly and facilitate change by mitigating specific precipitating factors, it is argued that organisational necessity dominates, potentially restricting understandings and responses to 'managerial dictates and guidelines' (Wilson, 2002, p. 12), derived from organisational rather than professional imperatives (Schiamberg \& Gans, 2000).

\section{An alternative - a structural approach to definition}

While a joint connotative/ denotative approach suggests elder abuse and neglect is broadly understood, the literature reveals an ambiguity stemming from:

- Variations in interpretation as to what commonly used terms signify, and

- A lack of separation across the spectrum of 'agreed' categories (Schiamberg \& Gans 2000). 
A structural approach to definition has been documented by Stones (as cited in Nahmiash 2002) and extended by Nahmiash (2002), Wilson (2002) and the World Health Organisation (2002). This approach proposes that, no matter the type, elder mistreatment is a result of behaviour which is contrary to the 'expectations and norms' of society. This highlights the importance of understanding:

- What is expected of elders, and

- How standards and expectations, as they relate to older citizens, are shaped and reshaped across time, place and context.

It is argued that if elder abuse and neglect is to be more completely understood, expectations and norms as they relate to older people, and how and by whom these are shaped and reshaped across time, place and context must be scrutinised. This position acknowledges that elder mistreatment is located in the cultural, social, economic, religious, gender and political (Aitken \& Griffin, 1996; Penhale, 1999; WHO, 2002; Schofield, 2004; Hightower, Smith \& Hightower, 2006; Fallon, 2006; MOH, 2007) contexts in which it is defined and viewed, as it is within these contexts that personal experiences are lived and value judgements and theoretical assumptions are made by those charged with making a response. The WHO Missing Voices report (2002) concurred, commenting on the need to move from an individualistic approach to one which considers the 'structural-societal factors' (p. 8) which acknowledges more fully the socially constructed complexity of elder abuse and neglect.

\section{The challenges facing practitioners}

\section{Known and ordered or complex and dynamic - implications for practice?}

The connotative/denotative argument has prevailed with a corresponding perception of certainty evolving from documented guidelines designed to inform practitioners and steer their course of action. Social work practitioners are encouraged to use standardised, 'known' procedures as a mechanism to manage and intervene, with certainty, in cases of elder mistreatment (Pritchard, 1999; $\mathrm{MOH}, 2007)$. This drive for certainty leads to suggestions that:

- Being 'old' is a distinguishing characteristic and observable cause of elder mistreatment (Harbison, 1999).

- We agree on what constitutes 'best practice' in respect of 'elder abuse and neglect', and

- As well as meeting organisational accountabilities, technical correctness and procedural rigor ensures 'best practice'.

Guidelines appear to offer practitioners and policy makers a degree of sureness informing them, and the communities they serve, that 'elder abuse and neglect' can be known, ordered and managed (Maher, 2005; $\mathrm{MoH}, 2007)$.

However despite guidelines, practitioners report hesitancy (Schiamberg \& Gans, 2000; Maher, 2005). What this positivist approach fails to fully account for is the alternate discourse of contestability which positions elder mistreatment as a contextual phenomenon emerging from dynamic interactions between individuals who are subject to multifaceted 'structuralsocietal factors' (WHO, 2002, p. 8). Such contestability brings into focus ethical social work practice, with practitioners exploring, on a daily basis, the dynamic interactions between individuals and society (ANZASW, 2008) in a way that attaches importance to recognising 
human and civil rights, and practice which attends to the principles of dignity, worth and respect (Roberts, 2008; ANZASW, 2008) in regards to older people. Viewed from this perspective, elder mistreatment must be considered a kaleidoscope of issues which is scrutinised through various lenses by a variety of people - including social work practitioners. This approach implies that to more completely understand, elder abuse and neglect needs to be located in context. This position exposes the possibility that practitioners may be open to a raft of influences which impact on their practice as they grapple with elder mistreatment.

\section{The challenge created by a 'cultural attitude of ageism'}

Whether viewed as known and ordered or complex and dynamic, practitioners are called upon to respond to circumstances which are potentially harmful and oppressive for older people. In doing so there is a belief that age is a significant factor and we know 'old'. This assumption is problematic. As Bytheway (1997, as cited in Victor, 2005) suggests, and McPhee and Bronstein (2002) and Harbison (1999), concur, 'old age' is often understood from an inherently ageist perspective based on stereotypical assumptions underpinned by a prevailing cultural attitude of ageism. It is suggested that ageism may have contributed to an 'expert-led' 'problem-focused' approach to elder mistreatment - one which potentially results in practice guidelines from which response can develop into 'recipes' (Estes, Biggs \& Phillipson, 2003, p. 32) for professional social work - the ingredients of which are not openly assessed.

Kane's (2006a, 2006b, 2008a, 2008b) research with social work and criminal justice students takes on significance here. Kane highlights a tendency for older clients to be assessed through an 'age filter' which endorses an ageist perspective (Kane, 2008a). Further, the claim that ageism, unlike other forms of discrimination, appears to be 'perceived as humorously sanctioned truthfulness' (Kane, 2008b, p. 31) is relevant. If applied to elder abuse practice, it is likely that such attitudes, if unchallenged, may serve to 'encourage discrimination, social inequity, segregation ...(and) restricted service delivery' (Kane, 2004, p. 779). On this basis it is reasonable to infer that a degree of ageism may, intentionally or unintentionally, colour practitioners' responses to elder mistreatment. This highlights the need for critical analysis and reflexivity in order that discriminatory beliefs are not routinely replicated in practice by perpetuating 'accepted wisdom' which discriminates on the basis of age.

A central challenge is for practitioners to constantly analyse all contexts, personal (including self), social, economic, political and cultural alongside organisational frameworks as it is the relationship between and amongst these elements that are the threads which make up the fabric of people's lives. Such a perspective reasons that social phenomena such as 'old' and 'elder abuse and neglect' are events which are experienced and / or witnessed by individuals (including practitioners) and therefore defined by individuals. This view echoes that of Pillemer \& Wolf (1986) who stated:

...even when the campaign against abuse is fiercely waged, it is important to retain the possibility that some portion of the war emanates ... from ... the larger forces that shape the fighters for justice (p. 18).

Here Pillemer and Wolf pose the question - whose needs are being met in the fight against 'elder abuse and neglect'? They point to the need for a re-examination of the influences impacting on practitioners who are the 'fighters for justice' (Pillemer \& Wolf, 1986; p.18), as these influences shape understanding and actions. 


\section{Conclusion}

Definitions, typologies and guidelines have served us well over the last 20 years as a beginning place to make sense and respond to elder mistreatment. Services and policy directives have emerged contributing to practice. These have undeniably provided options for intervention and resolution in circumstances where older people are abused or neglected. However, it is important to acknowledge that practitioners continue to report a lack of confidence despite guidelines and policies. It is time to explore this hesitancy in order that practitioners can understand more fully, and respond more effectively, to elder mistreatment. Not to explore further fails to fulfil professional expectations. As McPhee and Bronstein (2002) forcefully argue, social work professionals who fail:

'to acquire a more complex understanding of social conditions and incorporate this knowledge into ... social work interventions ... may ... serve to perpetuate and socially reproduce the very negative conditions they seek to eradicate' (p. 656).

It is essential that we seek, through critical analysis and reflexive processes, a greater understanding of elder abuse and neglect, and that these understandings are reflexively incorporated into practice. It is important that in doing so practitioners hold at the centre of their practice a concern for social justice which must form the basis of the profession's response to elder abuse and neglect.

\section{References}

Age Concern New Zealand. (1995). Elder abuse resource kit. Wellington: Age Concern New Zealand.

Age Concern New Zealand. (2004). Elder abuse and enduring power of attorney. Age Concern, 1-40.

Age Concern New Zealand. (2005). Age Concern Elder Abuse and Neglect Prevention Services: An analysis of referrals for the period:1 July 2002 to 30 June 2004. Age Concern 1-51.

Age Concern New Zealand. (2006). Media Release: Age Concern New Zealand, 9 June 2006: Age Concern New Zealand Incorporated.

Age Concern New Zealand. (2007). Elder abuse and neglect prevention: Challenges for future. Wellington: Age Concern New Zealand.

Aotearoa New Zealand Association of Social Workers. (2008). Code of ethics. Christchurch: Author.

Aitken, L., \& Griffin, G. (1996). Gender and elder abuse. London: Sage.

Block, M. R., \& Sinnot, J. D. (1979). The battered elder syndrome: An exploratory study. Washington DC: Department of Health, Education and Welfare.

Breckman, R. S., \& Adelman, R. D. (1988). Strategies for helping victims of elder mistreatment. London: Sage Publications.

Burston, G. R. (1975). Granny-battering. British Medical Journal, 6, 592.

Bytheway, W. (1997). Talking about age: the theoretical basis of social gerontology. In Jamieson, A., Harper, S. and Victor, C. (eds) Critical approaches to ageing and later life. Open University Press, Milton Keynes, Bucks: 7-15.

Decalmer, P., \& Glendenning, F. (1993). The mistreatment of elderly people. London: Sage Publications.

Durie, M. (2001). Mauri ora: The dynamics of Maori health. Auckland, New Zealand: Oxford University Press.

Estes, C., Biggs, S., \& Phillipson, C. (2003). Social theory, social policy and ageing: A critical introduction. London: Open University Press.

Fallon, P. (2006). Elder abuse and/or neglect literature review. Ministry of Social Development Te Manatu Whakahiato Ora - Centre for Social Research and Evaluation.

Families Commission. (2008). Elder abuse and neglect: exploration of risk and protective factors. Wellington: Author.

Fleischmann, P. (2008). Elder abuse: An emerging crime. (Public presentation, NZ Police Forum) Christchurch, New Zealand.

Fuller, T. T., \& O'Malley, T. A. (1987). Inadequate care of the elderly: A health care perspective on abuse and neglect. New York: Springer.

Harbison, J., \& Morrow, M. (1998). Re-examining the social construction of 'elder abuse and neglect': A Canadian perspective. Ageing and Society, 18, 691-711.

Harbison, J. (1999). Models of intervention for elder abuse and neglect': A Candian perspective on ageism, participation and empowerment. Journal of Abuse and Neglect, 10(3/4), 1-17. 
Harris, G. (2006). Domestic violence and abuse: elder abuse. Practice Nurse, 31(8), 59-63.

Hickey, T., \& Douglass, R. L. (1981). Mistreatment of the elderly in the domestic setting: An exploratory study. American Journal of Public Health, 71(5), 500-507.

Hightower. J., Smith, M. J., \& Hightower, H. (2006). Hearing the voices of abused women. Journal of Gerontological Social Work, 46(3/4), 205-227.

Kane, M. (2004). Ageism and intervention: What social work students believe about treating people differently because of age. Educational Gerontology, 30, 767-784.

Kane, M. (2006a). Social work students' perceptions about incompetence in elders. Journal of Gerontological Social Work, 47(3/4), 153-171.

Kane, M. (2006b). Ageism and gender among social work and criminal justice students. Educational Gerontology, $32,859-880$.

Kane, M. (2008a). When I'm 75 years old: Perceptions of social work students. Social Work in Health Care, 47(2), $185-213$.

Kane, M. (2008b). Imaging recovery, resilience, and vulnerability at 75: Perceptions of social work students. $E d u-$ cational Gerontology, 34, 30-59.

McKendry, J. (2007). Elder abuse and neglect prevention: Challenges for the future. Wellington: Age Concern New Zealand.

McPhee, D. M., \& Bronstein, L. (2002). Constructing meaning: Strengthening the policy-practice link. Social Work Education, 21(6), 651-662.

Maher, P. (2005). A study of social work practitioners and their needs when intervening in cases of elder abuse and neglect. (MA thesis). Christchurch: University of Canterbury.

Ministry of Health. (2002). Family violence intervention guidelines: Child and partner abuse. Wellington: Ministry of Health.

Ministry of Health. (2007). Family violence intervention guidelines: Elder abuse and neglect. Wellington: Ministry of Health.

Ministry of Social Policy. (2003). Positive ageing strategy. Wellington: Ministry of Social Policy.

Ministry of Social Development. (2002). Te Rito: New Zealand Family Violence Prevention Strategy. Wellington: Ministry of Social Development.

Ministry of Social Development. (2006). The New Zealand positive ageing strategy: Progress report 2006. Wellington: Ministry of Social Development.

Nahmiash, D. (2002). Powerlessness and abuse and neglect of older people. Journal of Elder Abuse and Neglect, 14(1), 21-47.

Ogg, J. (1993). Researching elder abuse in Britain. Journal of Elder Abuse and Neglect, 5(2), 37-53.

O'Malley, T. A., Everrett, D. E., O'Malley, H. C., \& Campion, E. W. (1983). Identifying and preventing family mediated abuse and neglect of elderly persons. Annals of International Medicine, 98, 998-1005.

O'Malley, T. A., Segel, H. D., \& Perez, R. (1979). Elder abuse in Massachusetts: A survey professionals and paraprofessionals. Massachusetts: Legal Research and Services for the Elderly.

Pain, R. (1997, March 1999). Theorising age in criminology: The case of home abuse. Paper presented at the British Criminology Conference, Belfast, Ireland.

Penhale, B. (1999). Elder abuse and older men: Towards an understanding. Paper presented at seminar: Men and violence against women, Strasbourg.

Peri, K., Fanslow, D. J., Hand, D. J., \& Parsons, J. (2008). Elder abuse and neglect: Exploration of risk and protective factors. Wellington: Families Commission: Komihana a whanau.

Pillemer, K. A., \& Wolf, R. S. (1986). Elder abuse: Conflict in the family. Massachusetts: Auburn House Publishing Company.

Pritchard, J. (1999). Lessons learnt in working with elder abuse. In J. Pritchard (Ed.), Elder abuse work: Best practice in Britain and Canada (pp. 13-39). London: Jessica Kingsley Publishers.

Rathbone-McCuan, E. (1980). Elderly victims of family violence and neglect. Social Casework, 61(5), $296-304$.

Roberts, J. (2008). The parameters of prejudice: Knowledge of ethics and age bias. Journal of Gerontological Social Work, 50(3/4), 65-79.

Schiamberg, L., \& Gans, D. (2000). Elder abuse by adult children: An applied ecological framework for understanding contextual risk factors and the intergenerational character of quality of life. International Journal of Ageing and Human Development, 50(4) 329-359.

Schofield, V. (2004). Elder abuse and neglect: Causes and consequences. Violence in Interpersonal Relationships, 80-95.

Stones, M.J. (1995). Porteé et definition des mauvias traitements et de la négligence a l'endroit des personnes agées au Canada, in MacLean (ed), Mauvais traitements aupres des personnes agées: strategies de changement. P 159-174. Montreal Editions Saint-Martin.

Thompson, K. (2008, June 30). Minister alarmed at alleged gagging. The Press, p. A2. Christchurch: Fairfax New Zealand.

Victor, C. (2005). The social context of ageing: A textbook of gerontology. Oxen: Routledge.

Wilson, G. (2002). Dilemmas and ethics: Social work practice in the detection and management of older women and men. Journal of Elder Abuse and Neglect, 14(1), 79-94.

World Health Organisation. (2002). Missing voices: Views of older persons on elder abuse. Geneva: WHO/INPEA. 